IBIMA Publishing

Journal of e-Learning and Higher Education

https://ibimapublishing.com/articles/JELHE/2021/919218/

Vol. 2021 (2021), Article ID 919218, 13 pages, ISSN : 2169-0359

DOI : $10.5171 / 2021.919218$

Research Article

\title{
Transition to Online Learning during COVID-19: What do Students Think?
}

\author{
Hiyam Al-Kilidar And Alan Sixsmith
}

The University of Technology Sydney

Correspondence should be addressed to: Hiyam Al-Kilidar; Hiyam.al-kilidar@uts.edu.au

Received date:22 September 2020; Accepted date:13 December 2020; Published date: 3 February 2021

Academic Editor: Ritesh Chugh

Copyright (C) 2021. Hiyam Al-Kilidar And Alan Sixsmith. Distributed under Creative Commons Attribution 4.0 International CC-BY 4.0

\begin{abstract}
This paper describes the transition from face-to-face to online delivery of a postgraduate project management subject in an Australian university that was necessitated due to the COVID-19 pandemic. As well as Presenting student reflections on these changes. General literature on learning delivery methods is presented as well as a commentary on the changes made to the delivery method in this PM subject. A standard student satisfaction survey (SFS), which is conducted each semester at our University, was used for data collection. Quantitative survey results are shown in comparison to the previous (Spring 2019) and current (Autumn 2020) teaching semesters. Four themes namely Communication, Content and Resources availability, Assessment and Weekly deliverables, as well as the Subject in General were derived from qualitative free format questions and reflective comments by students on their experience with the online delivery.
\end{abstract}

Keywords: Online Learning, COVID-19

\section{Introduction}

In their attempt to contain the spread of the coronavirus in March 2020, governments around the world, including Australia, mandated social distancing and restrictions on large gatherings. This severely affected the ability to deliver traditional face-to-face lectures at universities.

For the Autumn semester (early March to end June 2020) at our University, most subjects were initially planned to be delivered in the "normal" traditional faceto-face mode, comprising lectures and tutorials that included class activities and took place in lecture theatres and classrooms. Just one week after the start of the semester, and as a result of health advice from the Australian government, the decision was made not to have face-to-face classes for the remainder of the semester. This implied that subject delivery would need to be re-designed from traditional face-to-face delivery into online delivery.

Cite this Article as: Hiyam Al-Kilidar And Alan Sixsmith (2021)," Transition to Online Learning during COVID-19: What do Students Think?", Journal of e-Learning and Higher Education, Vol. 2021 (2021), Article ID 919218, DOI: $10.5171 / 2021.919218$ 
This decision to shift the teaching mode to online was relatively easy for our University as over the past few years, our university introduced measures of e-learning including blended learning and flipped classrooms that combine face-to-face lectures with the use of technology. The rationale behind this shift to the e-learning model included the positive impacts it has on aspects of accessibility, affordability, flexibility, learning pedagogy, life-long learning (Dhawan, 2020).

In a postgraduate project management subject of 142 students, the redesign of the subject delivery meant moving the lectures into live online zoom meetings and students' activities and collaborations also moved to an online environment. This provided a different student experience to what was originally planned prior to the start of the semester.

In this paper, we discuss how the subject delivery was modified and what were the impacts and reflections of students at the end of the semester. In section 2 , we present a literature appraisal of subject delivery methods. Section 3 outlines the changes to the delivery methods used in the subject, and section 4 summarises the research methodology and data collected by subject, faculty and university feedback surveys. In section 5 , we analyse the quantitative and qualitative collected data and present some of the student reflections on their experience in the subject. Limitations of this research and suggestions of future research are discussed in section 6 and Section 7 concludes the paper.

\section{Literature Review}

Online learning represents "learning experiences in synchronous or asynchronous environments using different devices (e.g., mobile phones, laptops, etc.) with internet access. In these environments, students can be anywhere (independent) to learn and interact with instructors and other students" (Dhawan, 2020: page 7). When pivoting from a traditional face to face teaching method to an online teaching method, a number of different learning methods are evident from the literature and indicate that 'eLearning' is broad and can be used to express many forms of digital content delivery. A cross section of these learning methods are listed below.

- Asynchronous eLearning - learning where student interaction occurs with a time delay and where participation is dependent on a student availability (Reform, 2017).

- Blended Learning - a combination of online and face-to-face delivery of learning mterials (Abdellatief, Sultan, Jabar, \& Abdullah, 2011; Leveaux, Gallagher, \& Sixsmith, 20160.

- Discussion Groups - allows for peerto-peer support and learning where subject matter experts can add their support to the discussion to enhance peer-to-peer learning (Selim, 2007).

- Distance Education - permits students to undertake self-paced learning of online content and usually there are no times set for distance classes (Jenkins et al., 2017).

- Self-Paced - learning which addresses the distinct learning needs and interests of individual students (Hill et al., 2014).

- $\quad$ Synchronous eLearning - learning where student interaction occurs at the same time (Chen, 2017).

- Live and Online - an online classroom led by an instructor that allows students to communicate, view presentations, interact with learning resources and work in groups (Radu, Southgate, Ortega, \& Smith, 2017).

Converting from classroom delivery to online delivery is not just the simple task of putting all content online. There are many complexities when undertaking this transition. To assist educators in shifting the 
focus of their delivery method, a fundamental understanding of education, instruction and learning design is essential. It is these three elements that work together to produce a positive student learning experience. As defined by van Merriënboer \& Kirschner, (2017), these three elements are:

1. The aim of instruction design is to enhance the appeal, usefulness and proficiency of learning experiences.

2. The focus of learning design is on the teaching and learning process that occurs during a class.

3. Education design when applied to the appropriate theory is the underpinning skill of the design of learning material design

Education design is the basis for both instruction and learning design and each may be considered interchangeable, depending on the environment encountered. While new instructional design concepts are necessary to help reinvigorate curriculum, many universities have struggled to effectively implement these educational and instructional changes (Alammary et al., 2014). A recent study conducted at Peking University (Bao, 2020) supports the instruction, learning and education design concepts as it identified five high-impact principles for online education. These principles are (a) high relevance between online instructional design and student learning, (b) effective delivery on online instructional information, (c) adequate support provided by faculty and teaching assistants to students; (d) high-quality participation to improve the breadth and depth of student's learning, and (e) contingency plan to deal with unexpected incidents of online education platforms.

Engaging students in an online delivery mode and/or in a blended delivery mode can become quite challenging given the instantaneous nature of information availability. A driver for adopting a blended learning approach is the fundamental need for students to gain work ready skills. As such, many Australian higher education institutions are incorporating authentic assessment items which utilise a combination of traditional classroom interactions coupled with eLearning-based activities that can enhance the student learning experience (Howitt \& Pegrum, 2015), thus enabling students to work together as they would in industry. This requires considerable time and effort from the academics and learning designers.

Situated learning (Lave, 1996) is a key element in engaging students in the learning process. Involvement in activities that augment learning outcomes allows students to grasp not only the intended educational outcomes but also the underlying context of the activity. Learning is then considered an experience which affords students the understanding and knowledge to ensure continued performance (Gallagher and Sixsmith, 2014).

Collaborative class work can be thought of as a foundation of situated learning as it improves communication and understanding between individual students in a group and between student groups (and between academics and students). In any organization, teamwork skills are crucial as most positions and projects inevitably involve working with others. Understanding how to work collaboratively in, or with, a team to solve problems, reach a consensus and communicate to varying audiences (Burmeister, 2015; Simpson, Nevile, \& Burmeister, 2003) is a key skill for any graduate. The ability to adapt to working with multiple and changing teams while working on different projects over different time periods is crucial for the contemporary IT professional (Al-Saggaf, Burmeister, \& Weckert, 2015).

Burns and Myhill advocate understanding subject content evolves from "interactive, social situations, scaffold by, and in collaboration with, others" (2004, p. 36). Further support for this concept comes from Tsui (2002) who suggests dialog enables a shared space for learning where students identify key aspects of a topic and the instructor obtains an appreciation of this learning experience and then attempts to broaden the common ground of understanding among all parties. 
Team members "collaborate interactively to achieve common goals" (Hertel et al, 2005: p71). Collaboration and cooperation between employees in the workplace is essential for organizations to function in their dynamic environments and to meet the demands of both their global and local market (Forret \& Love, 2008; Hertel et al, 2005; Majchrzak et al, 2005). The growth in the global marketplace has seen the use of distributed or virtual teams become increasingly important. As a member of a geographically dispersed team, it is extremely important to know your role within, and responsibility to, the team (Majchrzak et al 2005; Abdellatief, Sultan, Jabar, \& Abdullah, 2011; Schewe, 2005; Wan, 2012).

Educational paradigms have shifted "toward a perspective of learning involving participation in social interactions within the context of a community" (Enyedy and Goldberg 2004, p. 906). An enjoyable class will most likely see students attain improved outcomes, keep their interest high and hence their understanding of the content delivered is enhanced. Engaging students in the learning process is particularly relevant when undertaking subjects which deliver content that is not considered appropriate to their core field of study (Gallagher and Sixsmith, 2014).

Both Eom (2012) and Selwyn (2010) suggest educational technology has grown and appears dominated by the process of how people can learn with technology rather than how technology can complement learning. While technology use in education continues to evolve, conflicting findings have surfaced in regards to eLearning environments. To confuse the matter further, the terms distance learning and eLearning are often used interchangeably (Guri-Rosenblit, 2005, Selwyn, 2010) without giving consideration to the mechanisms used for content delivery. Distance education, by its definition, denotes the geographic separation of the learner from the instructor (Guri-Rosenblit, 2005), whereas eLearning is a tool to compliment face-toface teaching by delivering content and other instructional materials via technology.

In reviewing literature on technology use in an eLearning context, Saba (2012) states that an important goal of eLearning (online and/or in a blended delivery) is to deliver instructions that can produce equal or better outcomes than face-to-face learning systems, and that an understanding of systems quality, information quality and learning outcomes is required in the eLearning sphere. Wan (2012) notes eLearning has yet to make a significant impact on the quality of teaching and learning and pedagogical innovation. To date, the investments in eLearning tend to focus on the management of courses and are concerned with the automation of content delivery for teaching and learning. Conversely, Mar (2005) believes the major impact of eLearning is on the quality of content, which enables lifelong learning.

Selwyn (2010) points out that educational technology has become dominated by an interest in the process of how people learn rather than how the technology can assist the learning process. Educational technology can be challenging for academics, as finding the time to implement a new learning method into a specific course is complex and time consuming.

From the above it is evident that "E-learning is a situated activity that occurs in various settings and, if implemented appropriately, can provide an ideal environment facilitating social interaction whilst also providing academic, social, and psychological benefits." - (Chugh, 2010: p: 58).

\section{Delivery of postgraduate subject in the faculty of Engineering and IT}

The subject Managing Projects (MP) is a postgraduate subject in the Master of Engineering Management (MEM) program at the University of Technology Sydney (UTS). It is usually offered in a face-to face delivery mode once a week (3 hours) for 12 weeks. 


\section{Teaching and learning strategies}

The teaching and learning methods in the postgraduate subject Managing Projects (MP), together with the assessment items, are designed to allow students to apply and reflect on management topics and practices covered in the subject, and encourage brainstorming and investigation by students working in groups on weekly basis.

The fundamental approach to learning in this subject can be summarised as follows:

- Students focus on understanding rather than memorising

- Students exploring and testing ideas, without limiting themselves to textbook situations

- Students working collaboratively with their peers

To achieve the objectives of this subject, students are expected to prepare for the lecture through applying elements of a flipped classroom that includes private study and participation in class discussions and group work. A combination of weekly lecture presentations, discussions and assessment exercises are used to assist students in this endeavour. Through the use of these methods, students are introduced to general management principles that enable them to critically reflect on how these principles are applied in (simulated) real world scenarios. Students' experiences and readings would be reflected through active contributions to class and/or online discussions to facilitate self and peer learning.

Teaching and learning strategies and resources in the subject include:

- Weekly in-class sessions where students find out what they need to learn, follow worked examples, participate in discussions and practice principles and theories learnt as well as practice solving set problems and participate in group work.

- $\quad$ The Learning Management System (LMS), which for the identified subject is CANVAS, acts as a repository of subject resources including announcements on any updates and/or notices and a discussion board for communication with peers and staff general enquiries as well as submitting assessments and finding out marks.

- Assessments as a means to demonstrate knowledge and skills mapped to the subject learning outcomes.

- Private Study sets the expectation that for each hour of face-to-face contact students were expected to allocate 1.5 hours of private study that include review of lecture material, work on set exercises and assessments and join in discussions.

\section{Changes as a result of pandemic shut down}

In March 2020, just one week into the start of the semester, and as a result of the global pandemic and associated lock down in all Australian cities, a decision was made by the university to convert all subjects to online delivery.

This meant that there would no longer be face-to-face delivery of subjects at the university. The university halted teaching for one week in preparation to convert all face-to-face teaching delivery to online delivery for the remainder of the semester.

For the identified postgraduate subject in the Faculty of Engineering and IT, this meant that all subject assessments and learning outcomes remained unchanged, however, the original teaching and learning strategy of the weekly in-class session was modified as follows:

- Replaced with weekly live-andonline zoom meetings at the same scheduled time of the original faceto face lecture sessions. The lecturer decided to offer the session as an online lecture rather than make the online meeting a $\mathrm{Q}$ 
and A session. The lecture slides were shared with students a few days prior to each zoom session, and the lecturer offered presentations and explanation in an interactive style. This included Q and $A$, polls, breaking into breakout rooms for peer discussions and then presenting findings back to the whole class. In order to have minimal disruptions during the Zoom meeting, students were advised to use the chat box and/ or the raised hand symbol if they wished to ask/ answer questions, comment or contribute to discussions.

- For group collaborative work that was planned to take place in person, the zoom break out rooms were utilised for students to meet with their group mates to work on their group based activities and group work project.

- Online drop-in sessions were introduced to address any student questions/ doubts relating to subject or the assessments.

- In addition to the originally planned use of the LMS, short videos were recorded and/ or published to further illustrate certain concepts and solutions on CANVAS.

\section{Research Methodology}

The transition to 'live and online' delivery was a new experience for both students and teaching staff. We, therefore, decided to:

1. Gather and analyse quantitative information from the university's student feedback survey about the Autumn 2020 student cohort satisfaction rates and compare it with those of the student cohort of Spring 2019 (late July to early November). We will collect and analyse these data at 3 levels, (i) the subject (MP) level, the faculty level and the university level.
2. Gather and analyse detailed qualitative reflections about the student experience of the Autumn 2020 cohort based on the above changes that were implemented as a result of the subject's move into full online delivery.

\section{Discussion}

\section{Comparison of the Student Feedback Survey (SFS) results for Autumn 2020 and Spring 2019}

At the end of every academic semester, a standard online student feedback survey (SFS) is conducted by the university. The survey comprises statements that students rate based on a five-point Likert scale_(5 Strongly Agree, 4 - Agree, 3 - Neutral, 2 Disagree and 1 - Strongly Disagree), the Statements were:

1. The learning opportunities provided helped me meet the stated objectives of this subject.

2. I made the most of my opportunities to learn in this subject.

3. Overall, I am satisfied with the quality of this subject.

4. The assessment tasks in this subject were directly related to the subject.

5. Overall, I received constructive feedback throughout this subject.

6. (In Autumn 2020 only) The subject provided opportunities to interact online with other students as part of my learning experience.

We will present and analyse the quantitative data collected from the SFS surveys for the Subject (MP), Faculty and University for the Autumn 2020 and compare them with those of the previous semester (Spring 2019).

The table below illustrates the number of students who participated in the survey for the MP subject and their average responses to the above-mentioned statements in Spring 2019 and Autumn 2020. 
Table 1: Comparison of quantitative results of student feedback surveys

\begin{tabular}{|c|c|c|c|c|c|c|}
\hline & \multicolumn{2}{|c|}{ Subject MP } & \multicolumn{2}{|c|}{ Across Faculty } & \multicolumn{2}{|c|}{ Across University } \\
\hline $\begin{array}{l}\text { Number of } \\
\text { surveys }\end{array}$ & 1 & 1 & 312 & 325 & 1752 & 1825 \\
\hline $\begin{array}{l}\text { No. of responses } \\
\text { (Response rate) }\end{array}$ & $\begin{array}{c}89 / 184 \\
(48 \%)\end{array}$ & $\begin{array}{l}46 / 102 \\
(45 \%)\end{array}$ & $\begin{array}{c}10077 / 2 \\
5442 \\
(40 \%)\end{array}$ & $\begin{array}{l}9121 / \\
27378 \\
(33 \%)\end{array}$ & $\begin{array}{c}38481 / \\
110302 \\
(35 \%)\end{array}$ & $\begin{array}{c}35436 / \\
109022 \\
(33 \%)\end{array}$ \\
\hline Statement \# & $\begin{array}{c}\text { Spring } \\
2019\end{array}$ & $\begin{array}{c}\text { Autumn } \\
2020\end{array}$ & $\begin{array}{c}\text { Spring } \\
2019\end{array}$ & $\begin{array}{c}\text { Autumn } \\
2020\end{array}$ & $\begin{array}{c}\text { Spring } \\
2019\end{array}$ & $\begin{array}{c}\text { Autumn } \\
2020\end{array}$ \\
\hline $\begin{array}{l}\text { S1 } \\
\text { (Std. Dev.) }\end{array}$ & $\begin{array}{c}4.27 \\
(0.77) \\
\end{array}$ & $\begin{array}{c}4.28 \\
(0.83) \\
\end{array}$ & $\begin{array}{c}4.07 \\
(1.02) \\
\end{array}$ & $\begin{array}{c}4.00 \\
(1.02) \\
\end{array}$ & $\begin{array}{c}4.13 \\
(0.94) \\
\end{array}$ & $\begin{array}{c}4.06 \\
(0.94)\end{array}$ \\
\hline $\begin{array}{l}\mathrm{S} 2 \\
\text { (Std. Dev.) }\end{array}$ & $\begin{array}{c}4.37 \\
(0.79)\end{array}$ & $\begin{array}{c}4.22 \\
(0.89)\end{array}$ & $\begin{array}{c}4.10 \\
(0.98)\end{array}$ & $\begin{array}{c}4.02 \\
(0.98)\end{array}$ & $\begin{array}{c}4.12 \\
(0.92)\end{array}$ & $\begin{array}{c}4.07 \\
(0.90)\end{array}$ \\
\hline $\begin{array}{l}\text { S3 } \\
\text { (Std. Dev.) }\end{array}$ & $\begin{array}{c}4.17 \\
(0.89) \\
\end{array}$ & $\begin{array}{c}4.09 \\
(1.07) \\
\end{array}$ & $\begin{array}{l}3.98 \\
(1.1)\end{array}$ & $\begin{array}{c}3.88 \\
(1.12) \\
\end{array}$ & $\begin{array}{c}4.04 \\
(1.04) \\
\end{array}$ & $\begin{array}{c}3.97 \\
(1.04) \\
\end{array}$ \\
\hline $\begin{array}{l}\text { S4 } \\
\text { (Std. Dev.) }\end{array}$ & $\begin{array}{c}4.40 \\
(0.73)\end{array}$ & $\begin{array}{c}4.26 \\
(0.91)\end{array}$ & $\begin{array}{c}4.24 \\
(0.91)\end{array}$ & $\begin{array}{c}4.33 \\
(0.85)\end{array}$ & $\begin{array}{c}4.24 \\
(0.88)\end{array}$ & $\begin{array}{c}4.30 \\
(0.83)\end{array}$ \\
\hline $\begin{array}{l}\text { S5 } \\
\text { (Std. Dev.) }\end{array}$ & $\begin{array}{c}4.29 \\
(0.76) \\
\end{array}$ & $\begin{array}{c}4.17 \\
(0.95) \\
\end{array}$ & $\begin{array}{c}4.04 \\
(1.05) \\
\end{array}$ & $\begin{array}{l}4.10 \\
(1.0)\end{array}$ & $\begin{array}{c}4.04 \\
(1.03) \\
\end{array}$ & $\begin{array}{c}3.95 \\
(1.08) \\
\end{array}$ \\
\hline $\begin{array}{l}\text { S6 (Autumn } \\
\text { 2020) } \\
\text { (Std. Dev.) }\end{array}$ & & $\begin{array}{c}4.13 \\
(0.98)\end{array}$ & & $\begin{array}{c}3.92 \\
(1.12)\end{array}$ & & $\begin{array}{c}3.94 \\
(1.09)\end{array}$ \\
\hline
\end{tabular}

For the MP subject, it is notable that there was a higher student participation in the survey of Spring 2019 than Autumn 2020. Except for a slightly higher result to the first question (The learning opportunities provided helped me meet the stated objectives of this subject), it is noticeable that all other results showed some decline in student satisfaction.

In regards to this decline, our interpretation revolves around the shift away from the traditional face-to-face method of the previous teaching semester. Students came into Autumn 2020 expecting a normal teaching semester, but due to the Covid-19 pandemic were instead automatically transitioned into a 'live and online' teaching mode that they were not familiar with.

Compared with results across faculty and University levels, students' response to the first statement (The learning opportunities provided helped me meet the stated objectives of this subject) showed a decline of (0.7) between Spring 2019 and Autumn 2020. Similar to the results noted in MP, decline in satisfaction was also apparent across faculty and university for the second (I made the most of my opportunities to learn in this subject) and third (Overall, I am satisfied with the quality of this subject) statements.

For statement 5 (Overall, I received constructive feedback throughout this subject), it is noted that MP recorded a higher satisfaction score (4.40) in Spring 2019 than the faculty and university average (4.24), however, this score dropped in Autumn 2020. This could be attributed to not having the immediate feedback given in face-to-face situations compared to the delayed asynchronous feedback that students received in online environments.

Statement 6 (The subject provided opportunities to interact online with other students as part of my learning experience) was introduced in Autumn 2020 to gauge student engagement with peers in an online environment without any face-to face contact. MP showed significantly higher scores (4.13) than the faculty and university averages of 3.92 and 3.94 respectively. This could be due to the group project that 
students needed to work on from week 2 till week 12 which provides them with the opportunity to engage, collaborate and discuss the various topics covered in the subject over most of the semester duration.

\section{Detailed Student reflections on curriculum changes and their impact}

As a reflective assignment, students were asked to provide a detailed reflective account on the teaching and learning resources and methods used in the MP subject, and to let us know what would have helped them in achieving the objectives of the subject. The aim was to obtain qualitative reactions and reflections from students at the end of the Autumn semester on their student experience during the semester.

From the qualitative data obtained from the reflective assignment, student reactions and reflections were grouped under the following themes: (1) Communication, (2) Content and Resources availability, (3) Assessment and Weekly deliverables, and (4) the Subject in General. Below some student quotes are included for each theme:

\section{Communication}

Almost all student responses stressed the importance of clear and frequent communication contributing to a positive student experience. Comments included:

- "The staff was always available on if we had any query regarding some assignments or any other resources related to subject. The description of every assignment was clear so that every enrolled student can understand it with ease."

- $\quad$ "Support from UTS, teaching faculty and most importantly from the team members motivated me and pushed me positively to achieve my objective of passing the subject with good grades".

- "I liked that most doubts could be cleared through direct contact with subject co-ordinators, both in ongoing class and through e-mail as well".
- "Modules, assignments, marks, groups, and even the comment section, all the sections were clear and useful. Tutors were highly active online in case of any doubt through canvas and mails".

\section{Content and Resources availability}

When reflecting on the content and the available resources and their impact on the student experience, students pointed out and commented on the learning materials, Learning Management System, and Video content as follows:

\section{a. Learning Materials}

- "learning resources provided were apt and complemented the concepts taught in class well. It also helps that the learning materials are already available before the start of every session".

- $\quad$ "The content of the lecture is detailed and easy to understand by the explanation of the teacher".

- "learning resources were well set, and all the lecture slides were easy to understand and, at the same time, very informative".

- "The examples solved during the lecture gave us a clear idea of using the concept in a right way.

- $\quad$ "All the project management areas were covered in the subject and real life project was made available for better hands on experience".

\section{b. Learning Management System}

- $\quad$ "found that the CANVAS portal was well-structured and well-organised, allowing me to easily track and monitor activities during this semester. The discussion section was open to comment on subject activity questions and the answers were received considerably quickly".

- "All relevant resources were available from the beginning and discussion boards on canvas enabled a formal and public communication channel with the tutors".

- "Modules on Canvas provides listed key points, lecture slides, examples 
with solutions, some video resources form YouTube which are very helpful for students to know the learning outcomes and doing practice on their own".

\section{c. Video content / Online classes}

- "if you couldn't attend a lecture on time, you can get the video on the Canvas site".

- "I especially found the example videos on Canvas very helpful"

- "The advantage of the doing zoom classes are, it will save the travelling time and it will help to interact with everyone".

- "due to COVID-19 pandemic the classes and meeting were shifted to online classes but it was difficult to accept the reality at start but after few classes and meeting the new online module started making sense".

- "Online classes made listening to the lectures a lot easier while not being able to leave the office on Mondays. While seeing each other in person would have helped everyone with their group work, doing it online added a challenge that my group did well

- "The lectures, although online, were lively and interesting".

- "Lecturer provides a lot of learning materials on the CANVAS learning platform, and carefully prepared videos to help us understand each topic".

\section{Assessment and Weekly deliverable}

Upon reflecting on the subject assessments, it is apparent that students appreciated that the projects and cases resembled "real-life" scenarios. They particularly liked the weekly deliverables because they received weekly feedback that would be beneficial for their final report delivery. They also indicated that the use of templates helped them in their work in the subject. Their comments included:

\section{a. Continual case study (with weekly deliverables)}

- "it was a 'real' scenario"
- "Having weekly deliverables helps to organize yourself and devote time periodically to the subject",

- "The weekly deliverables ensure that students follow up the teaching process at all times, forcing students to keep following and learning, unable to slack off halfway"

- "the weekly deliverables are a good exercise to practice the learned knowledge on a real-life project".

b. Feedback

- "support and feedback that we received on our weekly deliverables and assignments are all exemplary".

- "I liked the way the tutor gave us feedback on deliverable and assignment".

- "After submitting homework every week, the teacher's feedback is also very helpful".

c. Group and Individual

- "Weekly deliverables in teams have cultivated students' sense of teamwork, promoted exchanges between students, promoted the collision of multiple cultures and enabled students to gain more meaningful knowledge".

- "The weekly deliverables made us keep track of the progress of the project weekly. This type of assignment makes the students work with groups more frequently and increases the contact between the group members".

- "The assignments, including both individual and group, played a big role in understanding the subject".

\section{d. Use of templates}

- "template for deliverables were very much clear and did not require any additional explanation".

- "Creating a template for all the assignments reduced the time and stress for students".

- "Assignment templates in MP49002 are of the best quality 
that I have ever used. The structures of templates are clear, the requirements for each part are clear. It would greatly lower the chances of students do not know what is required and greatly save the time of students to finish the task".

- "The templates are very helpful for each assignment. Students should have no difficulties of getting most of what is required by that assignment".

\section{The Overall Subject:}

When reflecting on the student experience in the MP subject ingeneral, it seemed that even though students found the online sessions to be interactive and engaging, they would still prefer the face-to-face experience. This was evidenced through comments such as:

- $\quad$ "classes were very interactive and engaging which made us want to attend every lecture to enrich our knowledge".

- "online classes were a bit of a struggle because I find it a bit hard to participate in class, but the professor has been helpful to make the online class more engaging".

- "Face to face learning is better than online learning, you can only spend so many hours in front of your computer being productive".

- "The amount of work is also intense for an online subject".

- "As a student who has been studying remotely, I am happy about the online learning resources and I can tell that the university has try the best to provide student services".

- "The last 15 minutes of every lecture kept for doubt solving helped me clear all my doubts and ask any additional assistance required for the subject".

\section{Subject Coordinator considerations}

It is not unexpected that the importance of clear and frequent communication contributed to a positive student experience in the subject. With the forced shift to 'live and online' learning, an enhanced level of communication between students and between academics and students was necessary to provide the same level of interaction that would have been present in a face-to-face class. This invariably mirrors the workplace where communication can be undertaken by various means. Burmeister (2015), Simpson, Nevile, \& Burmeister (2003) and Al-Saggaf, Burmeister, \& Weckert (2015), all suggest that communication is a key element for IT professionals (either individually or in a team) to functional professionally in the workplace.

It was encouraging that students considered the subject content and resources in a favourable way and that they found the online sessions to be interactive and engaging (even if many indicated they prefer the traditional face-to-face classroom experience). Burns and Myhill (2004) posit communication and collaboration with others (peers and academics) are essential elements for understanding subject content.

Engaging students in the learning process is often difficult and in a 'live and online' environment this can be quite challenging. Converting from classroom delivery to online delivery in a short period of time is not trouble-free as educators must think in terms of education, instruction and learning design (van Merriënboer \& Kirschner, 2017) as these three elements combined, produce a positive student learning experience. Learning activities and materials need to contain enough detail to assure learning outcomes are achieved as the onus is placed more on the student than the academic staff member. Lave (1996) suggests a concept of situated learning where the context of an activity plays an important role in the intended educational outcome. Gallagher and Sixsmith (2014) note a similar concept of the learning experience being fundamental to student understanding, learning and performance. 
Upon reflecting on the subject assessments, it is apparent that students appreciated that the projects and cases resembled 'real-life' scenarios. They particularly liked the weekly deliverables because they received weekly feedback that would be beneficial for their final report delivery. They also indicated that the use of templates helped them in their work in the subject.

Authentic assessment is crucial to engaging students in the learning process, be that fully online, a blended mode or the traditional classroom mode. Work ready skills are sought by many students during the studies, and the incorporation of authentic assessment items and situated learning experiences which resemble, or are based on, 'real-life' or industry like case studies and scenarios can enhance the student learning experience (Howitt \& Pegrum, 2015), and allow students to work together as they would in industry. As Burmeister (2015) notes any graduate entering the workplace must possess the ability to collaboratively work in, or with, a team.

\section{Limitations and Further Research}

The limitations of the paper centre around two elements. First is the fact that the data were derived from one subject taught over one semester. Second is that the quantitative data obtained came from a standard university survey - the SFS - and as such there was no ability to tailor the questions to the actual situation faced by the students in this particular PM subject.

Several avenues of future research are envisaged at this point in time. First, replicating the reflective assignment in another post graduate subject within our Faculty to obtain additional feedback on the transition to online learning from face-toface learning. Second, using the themes generated from this study (- namely Communication, Content and Resources availability, Assessment and Weekly deliverables, and the Subject in General) and those to be identified in the subsequent study, developing a targeted questionnaire for distribution to our student body through various cohorts of students such as post graduate, undergraduate, Faculty specific or University-wide.

\section{Conclusion}

This paper presented reflective thoughts on the change in delivery mode of a project management (PM) subject brought about by the global coronavirus pandemic. In comparing quantitative data between the last two (2) semesters (Spring 2019 and Autumn 2020), the results show there was a small downward shift in student satisfaction with the subject. However, the review of the qualitative data (the free format questions) would indicate that the new online learning method was well received and accepted by most students.

It is well understood that for many students the traditional face-to-face teaching method is superior. While one student commented 'face to face learning is better than online learning, you can only spend so many hours in front of your computer being productive', it must be remembered that, if not for the shift to online learning, Autumn 2020 may never have existed. Another student made a more supportive comment as follows: 'due to COVID-19 pandemic the classes and meeting were shifted to online classes but it was difficult to accept the reality at start but after few classes and meeting the new online module started making sense'. This encouraging comment indicates students are willing to adapt to the circumstances they face to continue their education.

\section{References}

- $\quad$ Abdellatief, M., Sultan, A., Jabar, M. A., \& Abdullah, R. (2011). A Technique for Quality Evaluation of E-Learning from a Developers Perspective. American Journal of Economics and Business Administration, 3(1), 157-164.

- Alammary, A., Sheard, J., \& Carbone, A. (2014). Blended learning in higher education: Three different design approaches. Australasian Journal of Educational Technology, 30(4).

- Al-Saggaf, Y; Burmeister, O. \& Weckert, J. (2015) Reasons behind unethical behaviour in the Australian ICT 
workplace; Journal of Information, Communication and Ethics in Society, (13, 3-4), pp. 235-255(21)

- Bao W. (2020). COVID-19 and online teaching in higher education: A case study of Peking University. Hum Behav \& Emerg Tech. ;2:113-115. https://doi.org/10.1002/hbe2.191.

- Burmeister, O. K. (2015). Improving professional IT doctorate completion rates. Australasian Journal of Information Systems, 19, 55-70. doi: 10.3127/ajis.v19i0.1073

- Burns, C., \& Myhill, D. (2004). Interactive or inactive? a consideration of the nature of interaction in whole class teaching. Cambridge Journal of Education, 34(1), 35-49.

- Chen, I.-S. (2017). Work engagement and its antecedents and consequences: A case of lecturers teaching synchronous distance education courses. Computers in Human Behavior, 72, 655-663.

- Chugh, R. (2010). E-learning Tools and Their Impact on Pedagogy. Ubha, DS \& Kaur J (eds), Emerging Paradigms in Commerce and Management Education. GSSDGS Khalsa College Press, pp. 28-81, ISBN: 978-81-909755-2-0.

- Dhawan, Shivangi (2020). Online Learning: A Panacea in the Time of COVID-19 Crisis. Journal of Educational Technology Systems 2020, Vol. 49(1) 522.

- Enyedy., N., \& Goldberg, J. (2004). "Inquiry in Interaction: how local adaptions of curricula shape classroom communities". Journal of Research in Science Teaching, 41(1), 905 -935.

- Eom, S. (2012). Effects of LMS, selfefficacy, and self-regulated learning on LMS effectiveness in business education. Journal of International Education in Business, 5(2), 129-144.

- $\quad$ Forret, M. \& Love, M.S. (2008) Employee justice perceptions and coworker relationships, Leadership \& Organization Development Journal, (29, 3), pp. 248-260.

- Gallagher, S., \& Sixsmith, A. (2014). Engaging IT undergraduates in non-IT content: adopting an eLearning information system in the classroom.
Interactive Technology and Smart Education, 11(2).

- Guri-Rosenblit, S. (2005). 'Distance Education' and 'e-learning': Not the same thing. Higher Education, 49(2005), 467 - 493.

- Hertel, G., Geisterb, S. \& Konradtb, U. (2008) Managing Virtual Teams: A Review of Current Empirical Research, Human Resource Management Review, (15), pp. 69-95.

- $\quad$ Hill, C. W., Jones, G. R., \& Schilling, M. A. (2014). Strategic management: theory: an integrated approach: Cengage Learning.

- $\quad$ Howitt, C. \& Pegrum, M. (2015) Implementing a flipped classroom approach in postgraduate education: An unexpected journey into pedagogical redesign, Australasian Journal of Educational Technology, $(31,4) .458$

- Jenkins, J., Rumble, G., Murugan, K., Koul, B., Dodds, T., Peters, O., \& Perraton, H. (2017). Unit-9 Characteristics of Distance Education. In: IGNOU.

- Lave, J. (1996). Teaching, As Learning, In Practice. Mind, Culture and Activity, 3, $149-164$.

- $\quad$ Leveaux, R., Gallagher, S., \& Sixsmith, A. (2016). Creating a Situated Learning Environment in the Classroom for Final Year IT Students. Paper presented at the 28th IBIMA.

- Majchrzak, A., Beath, C. M., Lim, R., \& Chin, W. (2014). Managing client dialogues during information systems design to facilitate client learning.

- Mar, N. (2005). Utilizing Information and Communication Technologies to Achieve Lifelong Education for All: A Case Study of Myanmar. Educational Research for Policy and Practice, 3, 141166.

- Radu, I., Southgate, E., Ortega, F., \& Smith, S. (2017). Summary: 2017 IEEE virtual reality second workshop on $\mathrm{K}-12$ embodied learning through Virtual \& Augmented Reality (KELVAR). Paper presented at the K-12 Embodied Learning through Virtual \& Augmented Reality (KELVAR), 2017 IEEE Virtual Reality Workshop on. 
- Reform, E. (2017). The Glossary of Education Reform, for Journalists, Parents and Community Members. Retrieved from http://edglossary.org/asynchronouslearning/

- Saba, T. (2012). Implications of Elearning systems and self-efficiency on students outcomes: a model approach. Human-centric Computing and Information Sciences, 2(1), 6. doi:10.1186/2192-1962-2-6

- Selim, H. M. (2007). Critical success factors for e-learning acceptance: Confirmatory factor models. Computers \& Education, 49(2), 396-413.

- Selwyn, N. (2010). Looking beyond learning: notes towards the critical study of educational technology. 65 -
73. 2729.2009.00338

doi:10.1111/j.1365-

- $\quad$ Simpson, C., Nevile, L., \& Burmeister, 0. (2003). Doing Ethics: a universal technique in an accessibility context. Australasian Journal of Information Systems, 10(2), 127-133.

- Van Merriënboer, J. J., \& Kirschner, P. A. (2017). Ten steps to complex learning: A systematic approach to fourcomponent instructional design: Routledge.

- Wan, A. T. (2012). Impact of Personalized Recommendation and Social Comparison on Learning Behaviours and Outcomes. Paper presented at the 23rd Australasian Conference on Information Systems, Geelong. 